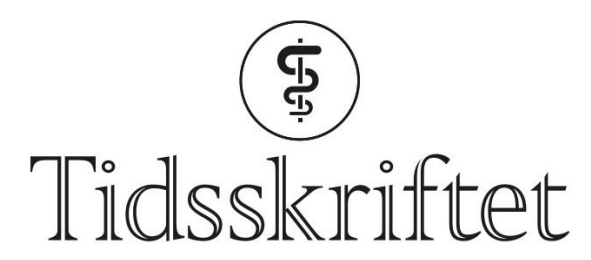

DEN NORSKE LEGEFORENING

\title{
En robust kombinasjon
}

INTERVJU

HELEN BRANDSTORP

E-post: helen.brandstorp@uit.no

Britt Larsen Mehmi er en av de erfarne «kombilegene» i Finnmark, en som har vært der over tid. Stimulerer hennes lokalt integrerte virke de kvaliteter som ordet robust opprinnelig beskriver?

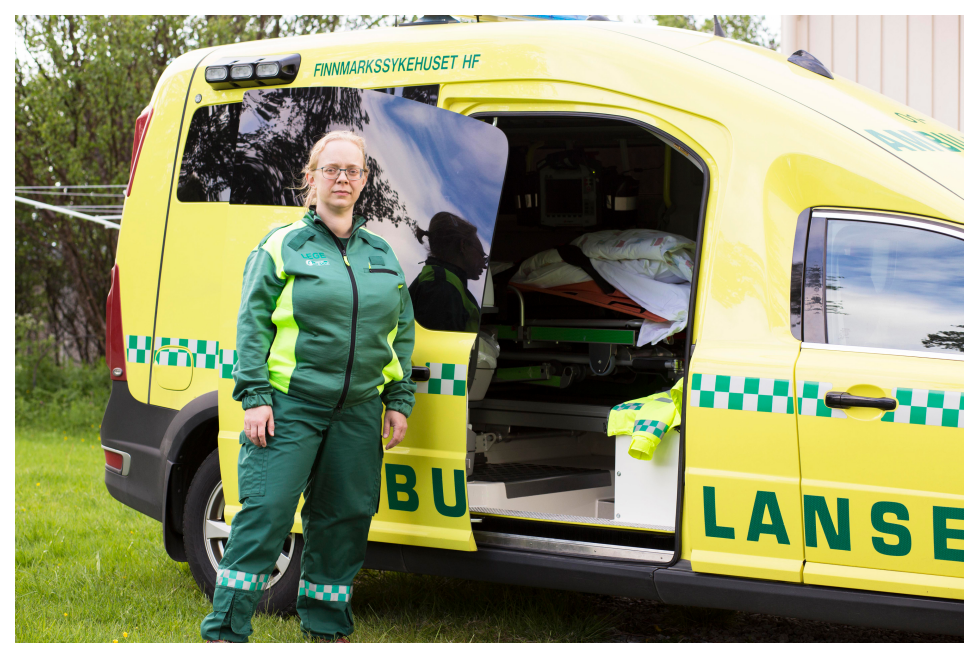

Alle foto: Susanne Hcetta.

Hardt tre eller eik er den opprinnelige betydningen av ordet robust. Å være robust vil således si å ha solid bakkekontakt og vokse langsomt. Robuste tåler en støyt, strekker seg både utover, oppover og nedover, og har et virke som brenner lenge. Dette er kvaliteter og prosesser som man må tett på for å få med seg.

I løpet av intervjuet med Britt Larsen Mehmi viser det seg at begge parter har en interesse for fenomenet legevekst. Kanskje er denne veksten knyttet til det store ansvaret som preger legejobber flest?

\section{Deltager}

Britt Larsen Mehmi er en såkalt kombilege. Hun er både fastlege og kommuneoverlege, en kombinasjon som finnes i de mange vanlige kommunene i landet - de som ikke er storbyer. Som både samfunns- og allmennmedisiner deltar Britt helt praktisk i tjenestene hun har systemansvar for og utvikler daglig sin lokalkompetanse og relasjoner blant befolkningen så vel som forvaltningen. Kontinuitet og bygging av tillit i lege-kommune-forholdet er viktig, slik det er i lege-pasient-forholdet.

Mehmi har dessuten ikke fritak fra vakter i legevaktordningen, men deltar også der - slik 
leger flest gjør i de minst sentrale kommunene. Dette tydelig integrerte virket representerer motsatsen til det Fugelli kalte «engangsleger». Det dirrer da Britt forteller om håndtering av drap og andre tragiske dødsfall i den lille byen.

\section{Britt Larsen Mehmi}

Født 1979 i Tønsberg

Cand.med. fra Royal College of Surgeons in Ireland, Dublin 2004

Turnustjeneste ved Tønsberg sykehus 2004-05 og i Vadsø kommune 2005-06

Assistentlege, anestesiavdelingen, Sykehuset Østfold, Fredrikstad 2006-07

Fastlegevikar, Tana og Nesseby kommuner 2007-09

Fastlege, Vadsø kommune siden 2009

Kommuneoverlege, Vadsø kommune siden 2010

Spesialist i allmennmedisin 2012

LIS3-lege i samfunnsmedisin

Kommunalt medlem av Overordnet Samarbeidsorgan Finnmark

\section{Kulturmøter}

Det var kommuneturnus i Vadsø som rekrutterte den unge legen fra Vestfold. Hun falt for den avslappede livsstilen i Øst-Finnmark - og en postmann med et åpent blikk og bredt smil. Etter litt tid som anestesilege i sør, vendte hun tilbake.

- Jeg skrev veldig mange brev som jeg måtte levere personlig på posten i løpet av turnustiden, sier Britt og ler slik hun pleier.

Mannen som tok imot i postluken, Ricky, åpnet til slutt hele favnen. Brudebildene fra et fremmed kontinent viser et ungt par som ikke har latt seg skremme av det ukjente.

Brudgommen er indisk, og bruden er vakkert pyntet etter alle hans lands skikker, med sminke og de lekreste silker. Ricky har siden byttet arbeid, fått mer ansvar og er typisk nok på reise når Britt inviterer hjem etter jobb. Her oppe er det gjerne Widerøes flyruter som avgjør om man rekker hjem til middag.

\section{Gjør det meste}

Selv går Britt fra kontoret halv fire, via barnehagen og hjem til familien. Også når hun har vakt. - Jeg mener at ledelsen i kommunen har skjønt det. Vi trenger tid til både familien og til pasientene våre. Legekontoret dekker en befolkning på om lag 6 ooo innbyggere, og vi er til sammen ti leger, fem sykepleiere, fem helsesekretærer og tre bioingeniører. Vi trenger denne kapasiteten for å drive god fastlegepraksis og egen legevakt. Etter at vi fikk den siste legehjemmelen, falt bruken av legevakt på kvelden. Slik skal det være. Legevakt er en beredskapsordning.

- Avstandene er for store til at legevaktsamarbeid med andre kommuner er en god løsning for oss. Vi har også alltid hatt muligheten til å legge inn pasienter på egen sykestue, eller kommunal akutt døgnenhet (KAD) som det vel heter nå. På dagtid gir vi både dialyse- og cellegiftbehandling, et samarbeidsopplegg med sykehuset.

- Noen ganger kan sykestua kanskje minne om en mini intensivavdeling. Britt ler igjen.

- Vi er vant til å gjøre mye selv på grunn av reiseavstandene. Jeg ringer gjerne sykehuskolleger for å få til et skikkelig behandlingsløp lokalt.

\section{Det er «vi» som har vakt}

Akuttmedisin er Britt Larsen Mehmis store faglige interessefelt. - Det er fordi jeg jobber her. Alt annet kan man ta etter hvert, men ikke det som haster. Selv om akuttmedisinen enkelte 
ganger er rett frem, nesten svart/hvitt, må man kunne jobbe i team og gi andres kompetanse rom. Det er ikke flaut om det er en annen som foreslår å måle blodsukker hvis jeg selv ikke har tenkt på det.

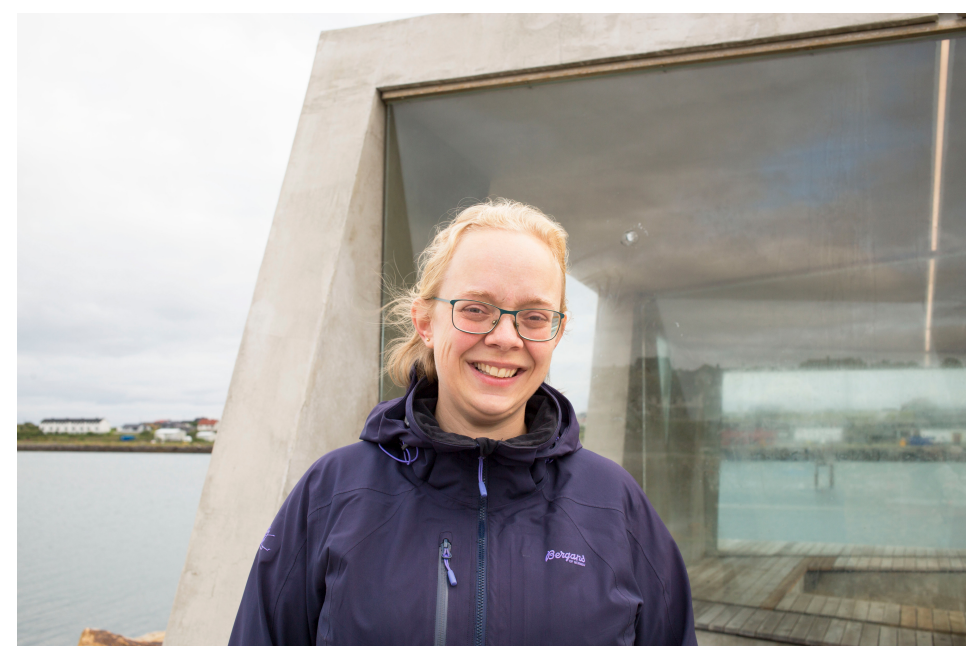

En kollega forteller at samtreningsøvelser med ambulansetjenesten lokalt skaper samhold i kollegiet: «vi vokser på det, det gir et godt arbeidsmiljø.»

Britt har såkalt "vaktkarma» som gjør at det gjerne er litt drama på hennes vakt. Men hun blir ikke redd lenger. I en artikkel forklarer Britt at hun ikke sier «jeg har vakt», men at «vi har vakt», og skriver: «Du er ikke på jobb alene; du er en del av et team som samarbeider for å ivareta pasienten. Og det teamet kan inkludere sykepleiere, fysioterapeuter, ergoterapeuter, bioingeniører, kanskje jordmor, helsesøster, ambulansepersonell, AMK, sykehusleger osv. Samtidig er det pasientansvarlig lege som tar beslutningene. Jeg tror det lærer oss å bli trygge og stå på egne ben».

- Allmennmedisinens hverdag som fastlege er allikevel det vanskeligste, synes jeg. Der går det i flere toner grått. Det er de uklare symptombildene som er virkelig vriene. Men det er ambulanseflysaken som stresser meg nå. Jeg har stått med dårlige unger på legevakten. Uten fly er det et mareritt, sier hun alvorlig og legger til:

- Jeg er jo mamma. Det ligger i bunnen av alt. Det er kjernen. Hva om det var et av mine barn?

\section{Ambulansefly på bakken}

Fredag 27. april i år lå Britt Larsen Mehmi og leste nyheter på telefonen før hun sovnet. Plutselig ble hun lys våken. «7 av 9 ambulansefly står på bakken», sto det i en lokal nettavis.

- Jeg ble først veldig forundret og så skikkelig sint. Jeg hadde ikke fått noen som helst beskjed om dette. Som kommuneoverlege burde jeg fått vite at vår akuttberedskap var alvorlig svekket. Etter en sjekk med kolleger via Messenger, skrev jeg en melding til alle i Finnmark legeforenings Facebook-gruppe .

- I løpet av den lørdagen brukte jeg sinnet mitt til å skrive et innlegg om dette til den nyetablerte nettsiden Fastlegen.no. Det var der jeg som fersk skribent turte å publisere. Dagen etter var den ute og spredte seg som ild i tørt gress.

Siden har det blitt mange uttalelser og tekster om dette fra nord, der seks av landets ni fly er stasjonert. - Fra kommunen vår i øst er det utenkelig å transportere et sykt barn i bil til barneavdelingen i Hammerfest i vest. Det er 6o mil én vei. Skal pasienten opereres av nevrokirurg eller få avansert intensiv behandling, må de til Troms $\emptyset$. Det er 80 mil på veien via Finland. Finnmark er jo større enn hele Danmark. Er det rart vi står på for å ha fly tilgjengelig?

Likevel finnes det lysglimt, innrømmer Mehmi. - Det har vært en helt ny opplevelse for meg at våre små stemmer fra lengst i nord høres på Stortinget. Tenk at vi kan påvirke nasjonal helsepolitikk! Sosiale medier er sånn sett en kjempehjelp. Jeg synes det er fantastisk 
morsomt å være en del av «Finnmarkslegene», som er en betegnelse et nasjonalt mediehus brukte i vår.

\section{Et sted for sterke kvinner}

- Har du tenkt på at «Finnmarkslegene» består av flest kvinnelige leger?

- Nei. Jeg har ikke reflektert over kjønn i det hele tatt, smiler Britt bredt. - Kjønn betyr ingen verdens ting i jobbsammenheng her. Kanskje det henger sammen med at jeg er trygg på meg selv også?

Vi tar et lokalhistorisk tilbakeblikk: For over 400 år siden ble vanlige kvinner fra småbygdene her hentet til dom og avstraffelse for hekseri på Steilneset i nabobyen Vardø. Hekseprosessene var blant de verste i hele Europa og sprang ut av retts- og religionstenkning fra steder langt, langt unna. Når samemisjonspresten Thomas von Westen kom reisende hele veien fra Trondheim om lag 100 år senere, skal han ha blitt slått av hvor mye makt kvinner hadde. Han likte det slett ikke.

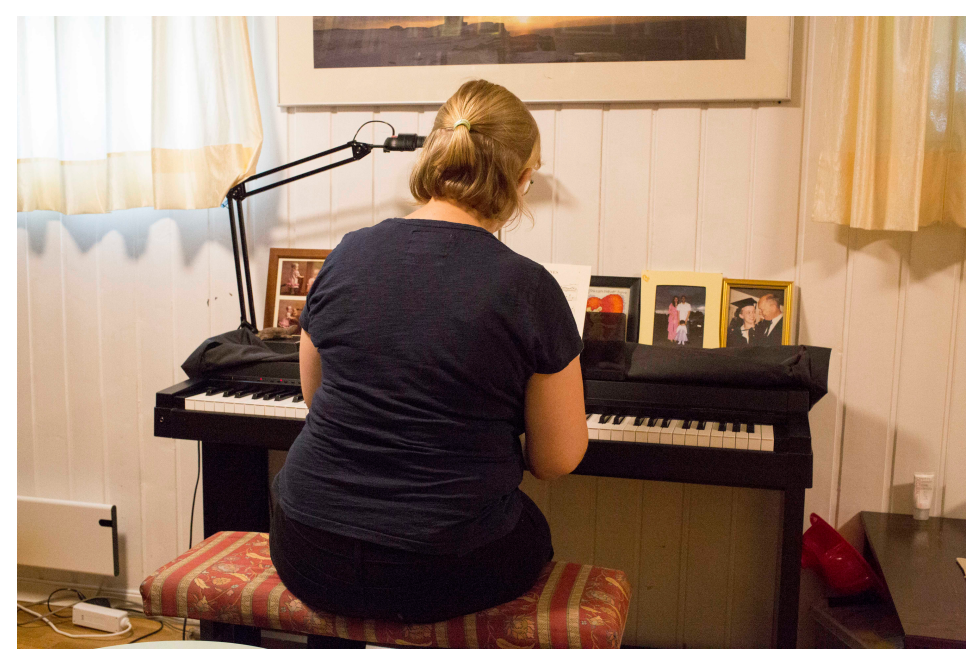

- Takk og lov for at man lever nå! Men jeg har jo sett kvinneundertrykkelse i mange varianter, særlig i India. Jeg har sett hvordan kvinner blir begrenset i sine valg og styrt av andre. De blir nok litt sjokkerte når de opplever meg med min klare tale og vilje. Jeg har vært mye sint der, men ikke på svigerfamilien min altså. Det gjør meg frustrert å oppleve urett som jeg ikke kan gjøre noe med. Det er litt den samme frustrasjonen jeg opplever når jeg besøker heksemonumentet i Vardø.

\section{Tørre å be om hjelp}

Britt har selv opplevd å miste en av sine nærmeste på brutalt vis. Da hun studerte medisin, fikk faren en svært alvorlig kreftdiagnose og døde bare fem uker senere.

- Det var helt forferdelig, men god oppfølging fra de på intensivavdelingen i Tønsberg gjorde at vi følte oss trygge. Jeg tror at motgang gjør meg sterkere. Jeg lærte noe viktig da. Jeg lærte hvordan vi som helsepersonell kan hjelpe dem som står i krisen ved å gi en dytt - helt forsiktig - i en retning som fungerer. Det kan handle om å takle følelser, mestre hverdagen eller si noen ord som trigger følelser slik at man blir i stand til å ta imot hjelp, sier hun og oppsummerer seg selv:

- Vi må faktisk hjelpe folk slik at de klarer å si fra om hva de behøver. De kan trenge hjelp til å få hull på den boblen de er i.

For Britt virker det som om det å søke hjelp selv er like naturlig som å gi andre hjelp. For eksempel har det alltid vært greit å ringe til kolleger hos fylkeslegen i samme by.

\section{Medisin er ikke matematikk}

Det var fra dette fylkeslegekontoret at gruppeveiledning for turnusleger i kommunene ble 
utviklet, som en støtteordning. Britt fryder seg over hvordan hun som kommunal veileder får se uerfarne vokse seg trygge, samtidig som hun selv lærer mye. Veiledning av legestudenter gjør dessuten kommunen til et attraktivt sted å søke jobb. Å få til dette krever ledelse.

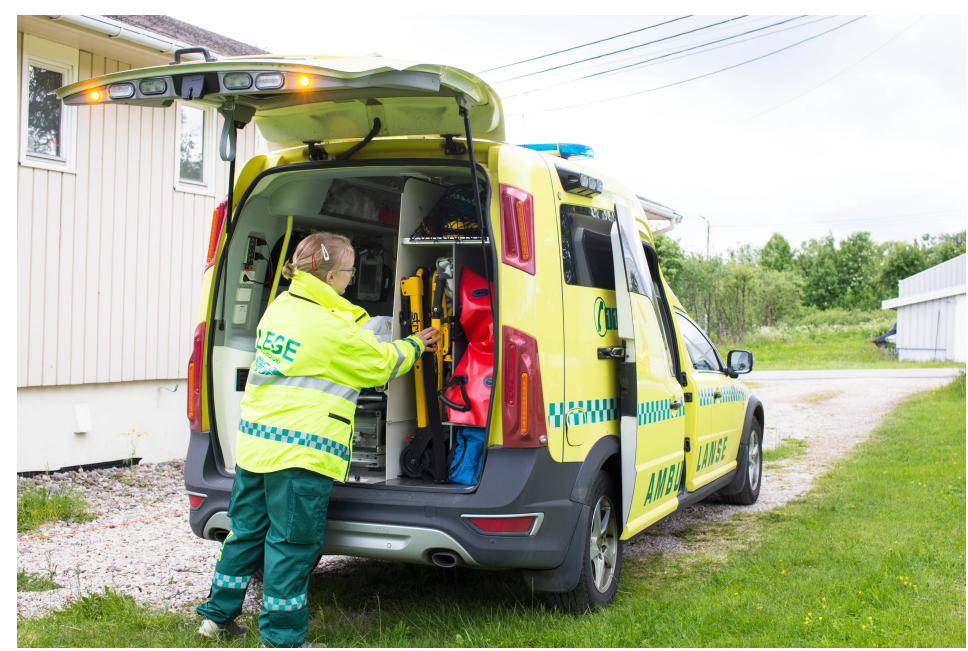

En kollega sier at Britt skaper trygghet med sitt jevnt gode humør. Hun roer heller ting ned enn å eskalere konflikter. Hun skaper rom for den enkelte.

- Jeg har alltid kontordøren åpen. Ikke når jeg har pasienter, selvfølgelig, men ellers. Det er stadig noen innom. Alle kan komme når som helst og snakke om hva som helst. Jeg vil gjerne lytte til det folk bærer på. Jeg har møtt folk som inspirerer, skaper glede og interesse for faget, men dessverre også personer som ikke har hatt den kapasiteten til å slippe andre inn.

Hun påpeker at medisin ikke er matematikk, og at man derfor bør bruke tid på å snakke seg frem til løsninger sammen. - Jeg tror det er viktig å innrømme at man ikke kan alt mulig og å prøve å sette ord på ting høyt. Selv om jeg har det travelt, får jeg det enda travlere om døren min er lukket.

En annen kollega sier at Britt gjerne avgrenser sitt ansvarsområde og gir andre mulighet til å fatte beslutninger, selv om de kanskje ville blitt annerledes om kommuneoverlegen var med. Avgrensningen er samtidig viktig for å ta vare på seg selv i en liten by der alle kjenner Britt.

- For å koble helt av koser jeg meg med ungene. Vi ler masse sammen. Og så liker jeg veldig godt musikk - både å synge i kor, spille piano eller klarinett. Det siste har jeg lært meg selv. Jeg tror faktisk jeg kan spille litt på nesten hva det skulle være, ler Britt upretensiøst.

\section{Hva er robust i nord?}

Britt Larsen Mehmi virker å trives godt med moderne «kombimedisin», musikk og kulturelt mangfold. Som metafor for det robuste passer kanskje en hvit, vakker reinrose bedre enn et eiketre. Treet klarer ikke klimaet. En reinrose derimot er en buskplante som tåler rå vind og kaldt vær og kan bli opp til hundre år gammel. Grenene kryper langsomt utover, men lite oppover. De danner en slags vev eller et teppe for å fange solen. Vann og feste får den gjennom en rot som går dypt, dypt ned i jorden. En kombinasjon som gir styrke og varighet. Det er noe alle her oppe vet. 